\title{
A Different Option for Neuromodulation Procedures: Sacral Nerve Stimulation
}

\author{
Nuri Süleyman ÖZYALÇIN \\ Algo, Pain Diagnosis and Treatment Center, Acıbadem Hospital, Istanbul, Turkey
}

\begin{abstract}
The aim of this article is to determine the effectiveness and the safety of sacral nerve stimulation on the several indications. Sacral nerve stimulation as a neuromodulation technique, is an effective and increasingly used therapeutic option. As a minimally invasive technique, many advances in the techniques for sacral neuromodulation have been described. The well-known indication of sacral nerve stimulation is the urinary voiding dysfunction. Although the mechanism of neuromodulation is still unclear, multipl new indications have been identified, include faecal incontinence, constipation, pain sydromes, interstitial cystitis, mixt urinary and bowel disoders, spinal injury and neurodegenerative disease, and sexual dysfunction. Since there is lack of high quality evidence of the procedure at present, good quality prospective, cross-over and randomize controlled studies are required to determine the true benefits of sacral nerve stimulation.

Keywords: Sacral nerve, stimulation, pelvic pain, incontinence, neuromodulation
\end{abstract}

\section{Introduction}

Pain treatment practices are classified into the following two groups: neurodestructive techniques and neuromodulation techniques. Neurodestructive techniques are the peripheral or central interruption of transmission in the pathways of pain transmission. These applications can be temporarily performed using local anesthetic agents or permanently performed using chemical agents, such as alcohol, phenol, glycerol, as well as physical applications such as heat and cold. Neuromodulation is the technique that enables the dynamic or functional repression of pain transmission. Electric currentbased stimulation techniques and pumping applications that enable drug delivery are also included in this group.
Sacral stimulation, the use of which as a neuromodulation technique has become increasingly common in recent years and which also has a special group of indications, is discussed in this study.

\section{History}

In the field of medicine, electrical applications, including treatment of pain, has a long past. Epitaphs of the Egyptian civilization in the $5^{\text {th }}$ dynasty era $(2750 \mathrm{BC})$ reveal that the electric catfish has been used in the treatment of pain (1). Furthermore, the use of Torpedo Marmorata, an electric fish, in pain treatment is mentioned in ancient Greek sources, including those by Aristotle (1). The use of these electric current-emitting fish in various pain treatment applications has been published in ancient Greek and Roman studies. 
The first person to discuss electromagnetic current applications in pain treatment was Gilbert, a scientist of the $17^{\text {th }}$ century, who used a magnetic metal to treat headache and mental illnesses and called it as a lodestone. Pieter van Musschenbroek, a Dutch scientist, was considered to have laid the foundation for modern neuromodulation practices using the Leyden jar, named after his university, in 1745 (2). Benjamin Franklin was the first scientist to perform neuromodulation applications in the United States of America (USA) based on the concept of the Leyden jar. Franklin's medical practices using high-voltage resulted in the development of ailments and skin wounds in volunteers, rather than facilitating pain treatment; therefore, these types of practices were abandoned, and this unsuccessful application led to the interruption of medical practices using electric current in the USA for several years.

The first modern electrostimulation practices began in the 1960s. During this period, Woolsey used electric current in animal research for the mapping of the cortex and subcortex. The gate control theory, defined by Wall and Melzack, constituted basic explanations regarding the mechanism of action of neurostimulation. Norman Shealy explained that an electric current modulates the nervous system and changes pain perception. Shealy prepared a platinum electrode and used its positive- and negative poles to control the pain experienced by a patient with end-stage cancer. An external cardiac generator was used in the abovementioned application, and it was found to be effective, regardless of the electrode being placed into the intrathecal cavity. Subsequently, Shealy et al. performed it epidurally, and the first electrode produced by Medtronic, Inc., gained approval [from the US Food and Drug Administration (FDA)] in the USA in 1968.

In the following years, deep brain stimulation was defined by Hosobuchi in 1973, and it was approved by FDA in 1977.

With regard to the historical development of sacral stimulation, a neuromodulation technique, the history of the first treatment practices using electric current for urinary incontinence, which was one of the first areas of indication of this practice, is as important as the historical development of spinal cord stimulation practices. One of the first publications in this area was the declaration by Giannuzzi in 1863 regarding the achievement of bladder regulation in dogs with spinal cord stimulation. Saxtoph's declaration regarding the treatment of his patients with intravesical stimulation in 1878 is also one of the first steps in treatment practices using electric current (3). Several interventional medical treatments, such as detrusor stimulation with transurethral approach, pelvic floor stimulation, and spinal cord stimulation, have been performed since the 1960s for bladder stimulation. In recent years, based on the studies conducted by Heine et al. (4) and Schmidt (5), the achievement of sphincter activity by S3 nerve root stimulation guided several studies. The first sacral neuromodulation application was performed by Feler et al. (6) in 1981, with indications of urinary incontinence, urinary frequency, and non-obstructive urinary retention. In addition, similar studies have been conducted for fecal incontinence $(7,8)$. As a result of the abovementioned studies, for patients with insufficient responses to other treatments, FDA approval in the USA was obtained for the management of urinary inconti- nence in 1997, the approval for the treatment of polyuria and urinary retention not caused by an obstruction was obtained in 2006, and the approval for fecal incontinence was obtained in 2011. Even though several researches are ongoing, particularly regarding the treatments of interstitial cystitis (IC) and chronic pelvic pain (CPP), they have still not reached the FDA approval stage. In the reimbursement list of the Social Security Institution of Turkey, sacral stimulation practices for urinary and fecal incontinences as well as for IC are approved. Reimbursements are made in the national social security system of our country for the indications of urinary and fecal incontinences, urinary retention, and interstitial cystitis.

\section{Mechanism of Action}

To understand the mechanism of action of sacral modulation and the logic for the treatment of medical problems that occur in this field, neuroanatomy of the area must be known. The pelvic plexus has a complicated structure that includes somatic, sympathetic, and parasympathetic nerves. These neuronal structures scatter to peripheral plexuses from the thoracolumbar region to the sacral region with a wide spinal cord transmission network. The sympathetic plexus of pelvic organs scatter from T12-L1, and most of them are carried by the superior hypogastric plexus. Conversely, parasympathetics take their roots from the sacral afferent parasympathetic system S2-4 and reach the organs via preganglionic pelvic splanchnic nerves. Afferent and efferent somatic innervation of the pelvis is by the S24. This wide area explains the complexity of the diseases of the pelvic region and the difficulty of treatment processes. Although not falling within the purview of this paper, medical treatments, physiotherapy methods, sympathetic- and somatic block applications, and surgical interventions used in treatment strategies are directed towards these complex neuronal mechanisms (6).

Mechanisms of neuromodulation applications are not completely known. Possible action in pain treatment is explained by the gate control theory. Furthermore, its effect on neurotransmitters in the descending control system serves as the evidence for this theory. Several theories are proposed to explain this issue. One of the most topical theories is the segmental gate control theory, despite the fact that it does not provide a detailed explanation of the role of electroneuromodulation in pain control. Although studies yielded results showing that neurostimulation has no effect on acute nociceptive pain, neurostimulation efficacy is also observed in acute pain models in some animal studies (9). Although the use of transcutaneous electrical stimulation device, which is a neurostimulation model, in postoperative analgesia applications as a supporting method can be cited as an example for this. When these findings are examined, it can be suggested that neuronal activity, which is formed in the dorsal horn (DH) with peripheral noxious stimulation, can be suppressed with dorsal colon stimulation (DC). Nevertheless, it has being discussed that this effect can be explained by revealing the antidromic activation of DC pathways, which take their roots from the cells in the $\mathrm{DH}$ lamina 3 and 4 . In a study conducted to clarify this issue, it has been shown that during the pain induced by squeezing, the noxious activation 
of spinothalamic tract neurons defined from the ventroposterior lateral thalamus can be repressed by DC stimulation (10). In this study, authors demonstrated that DC stimulation represses high-threshold nociceptive-specific spinothalamic tract cells with a more obvious selectivity in wide-dynamic-range (WDR) neurons. The efficacy of neurostimulation is reported to be related to supraspinal pathways (9). In modern studies, the relationship of the mechanism of action of neurostimulation on pain control with neurochemical structures, such as endorphin, serotonin, gamma-aminoburyric acid (GABA), and substance $P$, are also shown (9).

Electrical neuromodulation leads to the somatic afferent inhibition of the sensorial formation in the spinal cord. Pudendal nerve, which is the most known junction of the neural firing system, including filling and excretion dysfunction, is supported with the entries of afferent signals. Pudendal afferents can also block sacral spinal entries supraspinally, the inputs of descending sensorial pathways regarding hyperactive discharge. With regard to the abovementioned observations, direct suppression of postganglionic neurons, presynaptic suppression of primary afferents, suppression of spinal neurons that include the micturition reflex, and inhibition of interneurons that involve spinal segmental reflexes can indirectly suppress protective reflexes via internal sphincter sympathetic or external urethral sphincter interneurons closing bladder afferent entries. In addition, postganglionic stimulation can activate postganglionic neurons and induce bladder activation (thereby inducing discharge) as well as prevent bladder reflex by suppressing afferent interneuronal transmission (11).

We can understand electrical neuromodulation according to this neuroanatomical knowledge. The main innervation of anterior perineal muscles arises from the $\mathrm{S} 3$ level neuronal structures. Therefore, a selective $\mathrm{S3}$ stimulation is an appropriate target for the treatment of pelvic floor dysfunctions. However, all pelvic floor sensorial fibers are provided by the S2-4 and thoracolumbar sympathetic system. Therefore, the targets of stimulation for pain treatment in the pelvic region must include S2, S3, and $\mathrm{S} 4$ and must be bilateral, if necessary.

\section{Patient Selection}

Patient selection criteria vary depending on the indication of the application. These differences will be discussed in the indications section. However, the following are the general patient selection criteria that must be followed in all minimally invasive interventions, including neuromodulation practices; therefore, they are also applicable to sacral modulation:

1) Patients must not have benefited from valid medications, physiotherapies, and less invasive applications; in addition, indications for surgical intervention must not be present,

2) A serious, progressive, psychological disease must not be present in psychological evaluations,

3) A history of sexual or mental abuse that can negatively impact the treatment must not be present,

4) Patients must not have drug or substance addiction,

5) Diseases that will negatively impact the treatment, such as fibromyalgia and fatigue syndromes, must not be present,
6) Bleeding diathesis must be present and must be uncontrollable,

7) Systemic or local infection at the application site must not be present,

8) Patient or patient's relatives must not have educational or mental problems that affect compliance to treatment,

9) A success rate of more than $50 \%$ must have been achieved during the testing period.

In sacral modulation, electromagnetic interventions can damage the devices and cause tissue damage and patient injury. Electromagnetic applications used in daily lives are usually safe and do not cause problems. However, some diagnostic and therapeutic applications can cause problems. For instance, bone development stimulators, radiation therapy, and high-throughput ultrasonographic and laser applications can mainly damage the device. Diathermy and therapeutic ultrasounds, psychotherapeutic applications, electrocautery, defibrillation-cardioversion, and radiofrequency thermocoagulation ablation practices harm the patient and damage the device. In addition, the need for patients with electrodes and batteries for magnetic resonance (MR) imaging owing to the presence of other diseases poses an obstacle in using these systems. MR can harm the patient as well as damage the device. The device is turned off when MR needs to be used. Although there are MR-compatible devices at present, they are not common and are not suitable for some sacral stimulation models. The use of pacemakers can also be problematic. The patient's cardiologist must be consulted, and the two devices must be placed apart from each other and on opposite sides, if possible. It is recommended that diathermy devices should not be used because this can result in serious complications. Given that defibrillation is a vital intervention, the palettes must be placed away from the neurostimulators and perpendicular to the system; clinically, lowest energy and output must be used. The system is turned off prior to electrocautery use and is used as bipolar. If there remains only an option to use it as unipolar, it must be used with low voltage and low current, and the current path must be away from the pacemaker and electrode. During the neuroablation application to patients via $R F$, it must be away from the electrode and the device must be turned off (12).

Given that a significant proportion of patients who undergo urinary and fecal disorder treatments are of a young age, the use of electrical neuromodulation, particularly during pregnancies in female patients, remains to be controversial. Even though production companies state that electrical neuromodulation should not be performed during the pregnancy period, sufficient information regarding this issue is lacking. According to animal studies and experience with humans, the patient should be informed that the device activation must be terminated during pregnancy, and that the devices must be reactivated if fecal or urinary problems causing severe pain arise. In addition, patients should be informed that the device may be damaged during elective cesarean section operations, or that it can be misplaced during normal vaginal deliveries (13).

Dysfunctions that are similar to those in adults can arise in children. Major reconstructive surgery may be needed when 
anticholinergics are ineffective. In a study by Humphreys et al. (14), it was reported that sacral stimulation can also be used to treat the urinary problems of children (median age 11 years). The study demonstrates that the urinary incontinence problems resolve with a ratio of $75 \%$, nocturnal enuresis with a ratio of $83 \%$, and urinary retention with a ratio of $73 \%$.

\section{Indications}

The main indications of sacral electrical neuromodulation are urinary incontinence, retention, polyuria, and fecal incontinence. However, at present, it is accepted as an effective method in the treatment of pelvic pain syndromes and constipation.

\section{Pain}

Pelvic pain syndromes are health problems associated with difficult diagnoses and treatments. Several pelvic pains manifest as neurogenic inflammation and neuropathic pain.

Sacral electrical stimulation efficacy in different genitourinary pain has been documented in various studies. In the study by Feler et al. (15), sacral electrical stimulation has been argued to be an effective treatment in case of chronic non-bacterial prostatitis and epididimoorchialgia as well as vulvodynia pain. Mcjunkin et al. (16) reported effective neurostimulation results in neuropathic testicular pain. Kim et al. (17) published the successful sacral stimulation application results in patients with treatment-resistant cauda equina syndrome. In some studies, sacral stimulation application is observed to provide sufficient pain control in patients with anorectal pain $(18,19)$. Martellucci et al. (20) argued that sacral stimulation is effective in patients with various chronic pelvic pains, and that an effective response to pregabalin and gabapentin can be a predictive factor for successful treatment; in addition, the use of surgical staples may negatively impact the result. In a systematic research, neurostimulation applications are recommended to be effective, safe, and, in the long term, profitable treatments in chronic pelvic pain and bladder pain (21).

There are also studies regarding sacral stimulation applications in hip pain occurring outside pelvic structures. Kim and Moon (22) revealed in their case report that they achieved an effective result for pain caused by sacroiliac joint dysfunction by employing sacral stimulation performed via a retrograde approach.

As a serious pelvic syndrome, interstitial cystitis includes pain as well as urinary problems such as polyuria and difficulty in urination. Pain control is also established in patients with IC for whom sacral stimulation is performed for the treatment of urinary problems (23-25). Studies suggest that sacral electrical neuromodulation must be performed prior to major surgical interventions in patients with IC for whom conservative treatments were insufficient (26).

\section{Urinary Disorders}

To date, sacral stimulation is most commonly used in the treatment of urinary dysfunction. Initially, sacral stimulation was used in urinary urgency, incontinence, polyuria, and non-ob- structive urinary retention indications. At present, sacral stimulation is being used in the wider field of urinary disorders, including overactive bladder syndrome, with appropriate diagnostic criteria (27). It is recommended to be used in patients whose medical treatment was insufficient or in those who developed a tolerance to treatment as well as in those who do not respond to other treatment methods (28). In one of the first systematic studies on this issue, it was reported that sacral stimulation can be recommended as an effective and a safe method; however, more randomized blind trials are required for a more rigorous evaluation (29). In another meta-analysis regarding nonobstructive urinary retention, 14 studies were investigated, of which only one was randomized and 13 were observational; in addition, sacral modulation was concluded to be an effective method (30). In another meta-analysis in which only female patients were included, 30 randomized studies that included intravaginal stimulation, tibial nerve stimulation, and sacral neuromodulation as different treatment options were examined and sacral stimulation was demonstrated to be an effective method in resistant cases (31). The need for further studies has been stated in all of these studies, although the safety and efficacy of sacral neuromodulation in the treatment of urinary dysfunctions were observed.

\section{Gastrointestinal Disorders}

Treatments of dysfunctions, such as fecal incontinence and constipation, are the new indication areas of sacral neuromodulation therapy. Several studies were conducted in this area, and consequently, the FDA approved sacral neuromodulation for the treatment of fecal incontinence in 2011. However, an approval has not yet been granted for the treatment of constipation.

Fecal incontinence, which is generally considered to involve more problems than a single pathophysiological disorder, is a multifactorial condition. Sacral neuromodulation is generally performed for treating fecal incontinence in adult patients with intact sphincter integrity but with weak sphincter muscles (32). However, predictive factors that are necessary to reveal the efficacy of sacral neuromodulation prior to performing it remain to be unclear $(33,34)$. The efficacy of sacral neuromodulation in partial sphincter injury has also been demonstrated (35-37). In patients with scleroderma having proctitis caused by radiation and reduced rectal compliance owing to inflammatory bowel syndrome and in patients with anterior resection or previous rectal prolapse colectomy, the efficacy of sacral neuromodulation is demonstrated only in few studies (38-43).

Mechanism of action of sacral neuromodulation with regard to the treatment of constipation, particularly its effect on the feeling of defecation, is not yet completely clarified. This effect can be explained by the multi-dimensional parameters of sensorial, motor, and central neural pathways (43). The enhancing effect of the method on colonic motility is suggested to be effective in slow transit constipation (44). It is recommended as an effective treatment in persistent constipation cases (45). In a recent systematic study, 53 of 161 clinical studies that investigated cortical, gastrointestinal, rectal, and anal functions and 9 of 43 experimental studies were evaluated. Although sufficient 
information in this systematic study regarding the mechanism was lacking, it was concluded that the mechanism of action of sacral stimulation on anal dysfunction and constipation may be via pelvic afferents or a central effect, rather than primarily via peripheral motor neurostimulation (46).

A significant proportion of findings demonstrate that irritable bowel syndrome and other functional bowel diseases can be treated with sacral stimulation (43). Persistent diarrhea in irritable bowel syndrome can be brought under control via temporary sacral stimulation application (47).

In some patients, particularly in patients with spinal cord injuries, urinary and gastrointestinal disorders can occur together. Sacral stimulation application has been reported to be an effective method in such patients as well (48-52). However, in that case, electrode structure and stimulation parameters may be required to be adjusted according to the optimal values that are suitable for the patient and according to urinary findings (43).

\section{Other Indications}

The efficacy of sacral stimulation therapy is demonstrated in pelvic problems that arise in neurological disorders, such as multiple sclerosis and partial cord damage (50). Detrusor muscle hyperreflexia can develop in spinal cord damage. In one study, treatment rates of urinary problems and rectal problems were $87 \%$ and $60 \%$, respectively, during the long-term follow-up of patients with spinal damage who underwent sacral anterior root stimulation (51). In the study by Lombardi and Del Popolo (52), urinary complaints in incomplete spinal cord damage are reported to be efficiently treated with sacral neuromodulation. Positive effect of sacral stimulation in urinary dysfunction in Guillain-Barre syndrome, a demyelinating neurological disease, has been reported (53).

The increase in sexual activity that was observed in patients who underwent sacral stimulation due to a different indication led researchers to think that this application can also be used for this purpose in the future $(13,43)$. This phenomenon that was also observed in our applications is developing into an interesting field, but it may be problematic for clinicians. In some studies, it is argued that stimulation has an effect on male erectile dysfunction (54) and on orgasm ability via vaginal lubrication in female patients $(55,56)$.

\section{Technique}

Minimally invasive percutaneous techniques and surgical technique are defined as techniques in sacral stimulation applications. In this report, we will focus on percutaneous electrode applications. Minimally invasive percutaneous techniques include four techniques, namely retrograde, lumbar transforaminal, sacral transforaminal, and anterograde sacral hiatus approaches.

\section{The Retrograde Technique}

Following the retrograde electrode placement practice, which was first defined by Aló et al. (57), this technique has been commonly used in the last decade (58). In general, L2-3 or L3-4 levels are preferred for the sacral approach in this technique.
Intervention from the lower levels, particularly from the L5-S1 level, is difficult. After reaching the epidural region, electrode (s) are moved forward unilaterally or bilaterally in the cephalocaudal direction under the control of scope until S2, 3, or 4 level is reached. The disadvantage of the technique is the difficulty in moving the electrode forward because of the L5-S1 angle. Thus, dura damage or nerve damage can occur when moving the electrode forward. To avoid this problem, the angle is fixed by elevating the patient's lower pelvis. In the retrograde electrode steering similar to the lumbar transforaminal approach, spondylolisthesis, epidural operations, spina bifida formation, and epidural lipomatosis are considered as relative contraindications.

\section{The Lumbar Transforaminal Technique}

Similar to the retrograde technique, the electrode is moved towards the sacral roots in the cephalocaudal direction in this technique; entry to the epidural region is established via the lumbar transforaminal space (59). The difficulty in entering via the lumbar transforaminal space is one of the disadvantages of the technique. Furthermore, difficulties similar to those that arise while moving the electrode in the retrograde technique are experienced in this technique as well. Spinal root damage can occur during transforaminal entry and results in pain. Keeping the patient awake during the application as well as making the patient respond in case of a possible root contact can partially reduce this risk. The difficulty in fixing the electrode, thereby increasing the possibility of migration is another disadvantage. Additionally, other problems of the retrograde technique are also present.

\section{Sacral Transforaminal Technique}

The technique is executed by placing the electrode directly onto the targeted sacral root. This technique is new, and it is being widely used in recent years owing to the ease of use and safety (49). However, the fact that only one root is efficiently stimulated in this technique is purported to be a disadvantage compared with other techniques, particularly in applications of pain treatment $(59,60)$. However, there are studies demonstrating that $\mathrm{S} 3$ stimulation is effective on the pelvic floor plexus re-

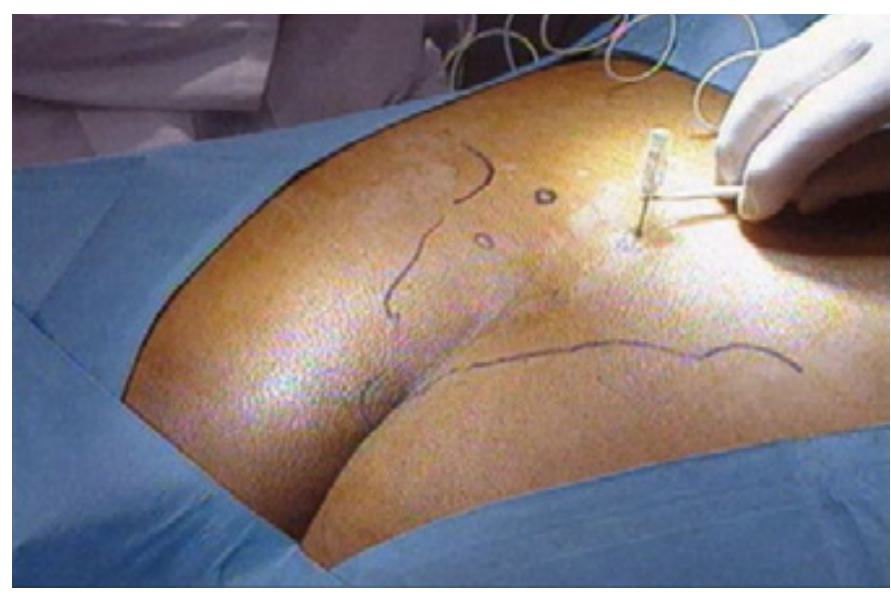

Figure 1. Marked structures in the patient 

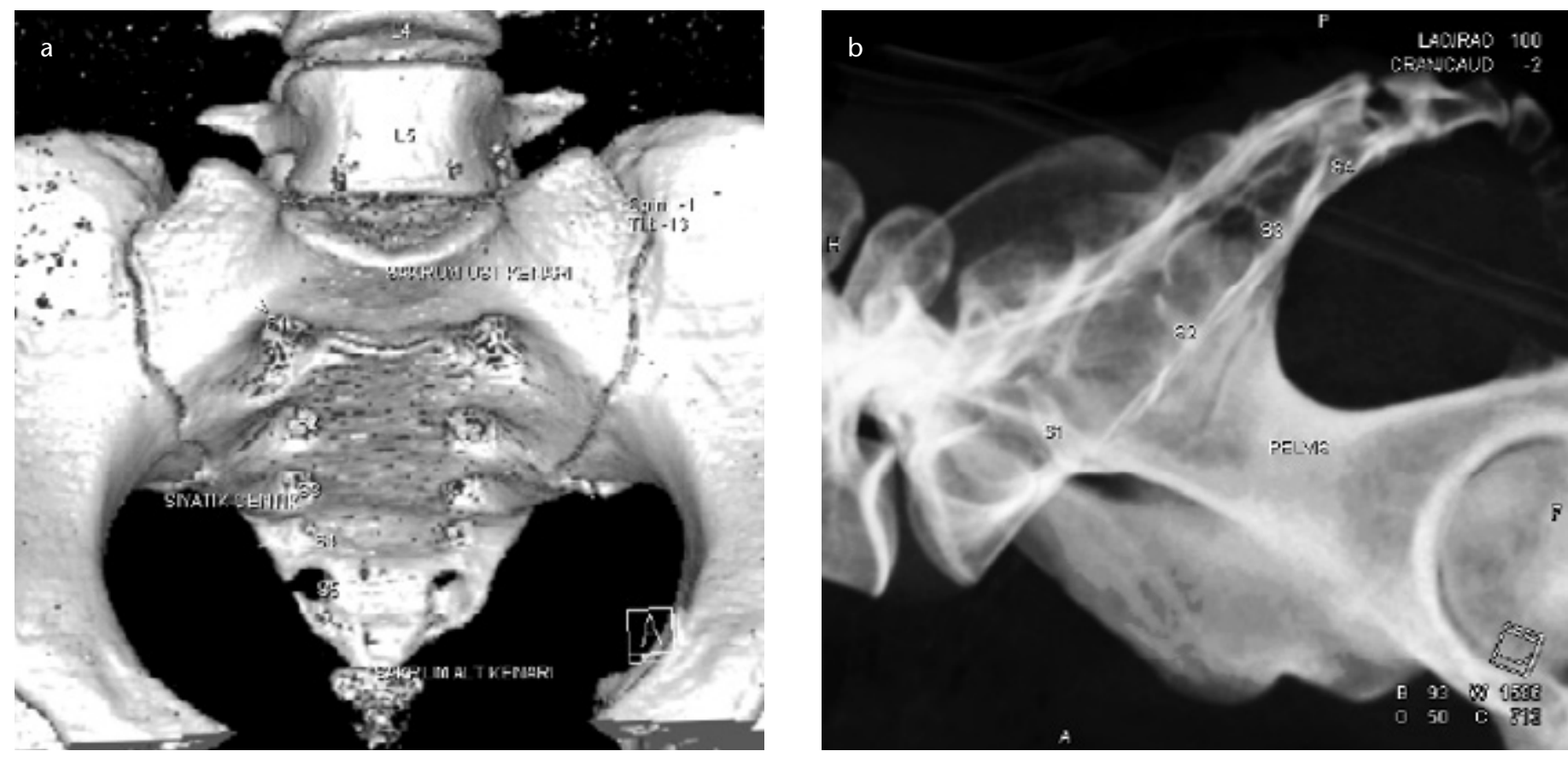

Figure 2. a, b. In PP image, sciatic notch and neuroforamen curves are viewed in the lower and upper margins of the sacrum (a), hump view on the inner border of the sacrum as observed in the lateral image (b) PP: pelvic pain

Table 1. Sensorial and motor responses of sacral roots

\begin{tabular}{|c|c|c|}
\hline Nerve root & Sensorial response & Motor response \\
\hline S2 & Sensorial stimulation on the vagina or penis floor & $\begin{array}{l}\text { Contractions in the anal sphincter, rotation in the leg/heel, } \\
\text { plantar flexion in the foot, contractions in the calf }\end{array}$ \\
\hline S3 & $\begin{array}{l}\text { Sensorial stimulation felt in the rectum and spread } \\
\text { into the scrotum or labium }\end{array}$ & $\begin{array}{l}\text { Inward contractions in the anus: fluctuations, plantar flexion in } \\
\text { the toe and sometimes in all fingers }\end{array}$ \\
\hline S4 & Sensorial stimulation only in the rectum & Fluctuations in the anus \\
\hline
\end{tabular}

gion, and that patients can easily tolerate this application as well as that it can be performed bilaterally, if needed (13).

For the application, L4 vertebra, upper and lower edge of the sacrum, bilateral iliac crests, posterior superior iliac processes, sciatic notches, and sacral midline are marked on the anteroposterior (AP) image (Figure 1). S1 is seen approximately at a distance of $1.5 \mathrm{~cm}$ lateral to the sacral midline at the top; S2 is seen at the level of posterior superior iliac processes, and the arc of S3 foramen is seen at the level of sciatic notches (Figure 2a), which is counted on the lateral image from S1, assuming that sacral vertebrae are of the same height. Accordingly, S3 foramen corresponds to the hump image that forms on the inner border of the sacrum (Figure 2b). After detecting S3 under scope control, the conductive needle is advanced to the front of the sacrum and passes the neuroforamen at an angle of $60^{\circ}$ to the plane of the skin, given that the upper foramens of the sacrum (S1 and S2) are horizontally located and the lower foramens are frontally located. After the needle is placed, the outer part of the needle is fixed using a sterile cable and stimuli are generated via a stimulus generator; S3 response is sought for an early test
(Figure 1, Table 1). When the abovementioned findings with the contribution of pudendal nerve stimulation and when S3 stimulation determined with plantar flexion that is apparent in the toe and rare in other fingers, which is accompanied by the mild stimulation of the sciatic nerve, along with fluctuation in the perineum are obtained, a guidewire is passed through the needle. The point where the needle is inserted into the skin is expanded with a bisturi, and the needle is removed by leaving the guide at that location. The cannula in which the electrode is placed and the radiopaque line on its tip is advanced via the guidewire until it reaches the anterior edge of the S3 foramen (Figures 3a-c). Subsequently, all the active edges of the electrode that are inserted through the cannula are placed on the anterior pelvic region. Each active edge of the electrode can be controlled by stimulation.

After this process is complete, to perform the long-term test, which is performed in all other techniques, the distal end of the electrode is joined to the extension cable and subcutaneously inserted; this connection is established using external current generators. The patient is discharged after a minimum of 1 

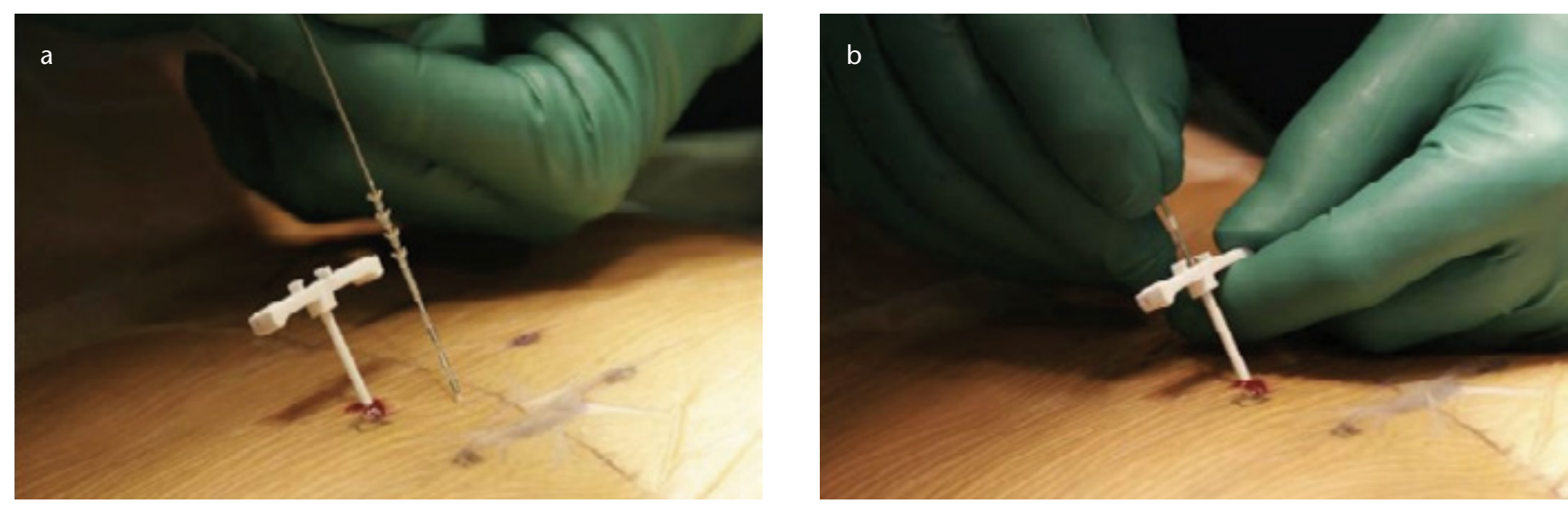

Figure 3. a, b. Guide cannula is inserted after obtaining a response (a), active edges of electrode are advanced through the cannula in a manner such that they are on the front surface of the sacrum (b)

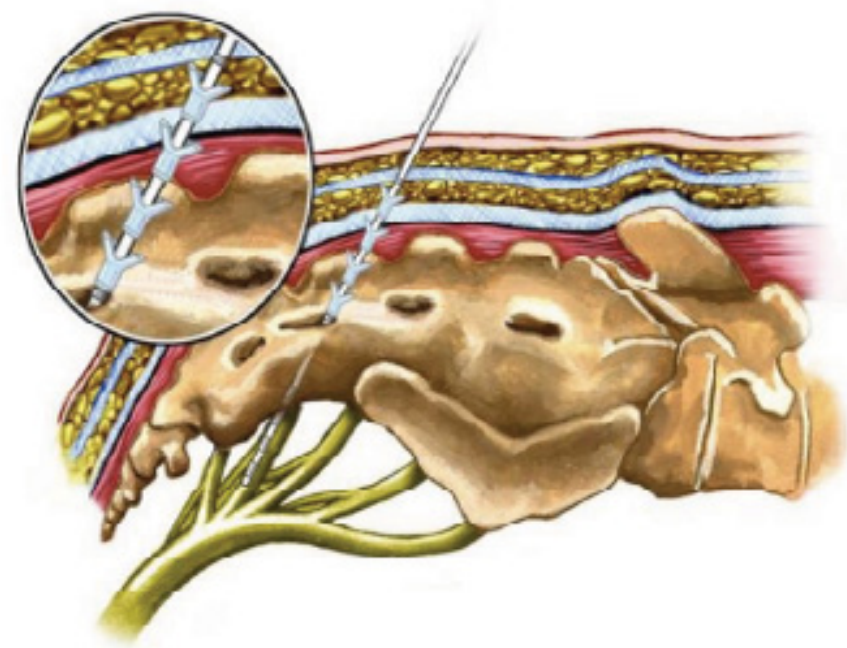

Figure 4. Schematic view of clamping catheter (Medtronic)

day post-application with the external current generator for the test period that will last for 2-4 weeks.

Nerve damage can occur with this technique. The risk of migration is present given that fixing the electrode is difficult. Decreasing lordosis by placing a cushion under the pelvis and communicating with the patient during the application to control the pain that occurs owing to the contact with the root facilitates the prevention of nerve damage. Furthermore, newly developed (Medtronic) clamping electrodes are effective in preventing migration (Figure 4).

\section{Anterograde Sacral Hiatus Technique}

In the anterograde approach, which is one of the newest techniques, the electrode is moved toward the sacral roots in the caudocephalad direction after entering via the sacral hiatus (61). The advantage of this technique is the ease of electrode placement (62). However, establishing electrode connections can be difficult. Furthermore, erosion can occur because of the insufficient subcutaneous tissues in weak patients. Other problems include anatomical differences in sacral hiatus such as obstruction or stenosis. These differences, which are frequently observed, can be preemptively visualized by an epidurogram that is traced by administering an opaque object. Finer needles through which the electrode can pass can be used in some hiatus obstructions; however, if stenosis is present, this technique cannot be performed. The hygiene of the anterior pelvic region is one of the most serious problems. The wider region including the entire hip, anal region, and perineum must be cleaned to prevent this. Despite this, the risk of infection is higher than that in other methods.

\section{Application Phases}

Preparation of the patient for the intervention is, regardless of the chosen technique, similar, despite some differences based on the experience of clinics. Sterilization rules are followed, patient selection criteria are heeded, interventions against possible problems are set up, and anesthesia and emergency intervention arrangements are present. The chosen technique is performed in the operation room where $\mathrm{C}$-arm scope and scope table are present; usually, the prone position is preferred during the intervention. Intervention area is prepared on the basis of sterilization rules. In our clinical applications, we ensure that the area is cleaned with povidone-iodine solution on one day prior to the operation, considering the hygiene of the area. The wider area is cleaned in a similar manner during intervention after waiting for a minimum of $5 \mathrm{~min}$. Subsequently, the patient is covered up, and the intervention area is covered with a sterile drape. Given that we perform the $\$ 3$ transforaminal technique, the patient is placed in the prone position in a manner in which the anus and the toes can be seen so that stimulation can be clearly observed. After placing the electrode, as described above, the activity is observed in three phases.

Acute phase involves receiving appropriate stimuli during electrode placement. After finding S3 with the help of scope control and marks, a stimulus is provided (Table 1). However, the intervention is repeated when an inappropriate response occurs. Electrode is placed when an appropriate stimulus is detected, 

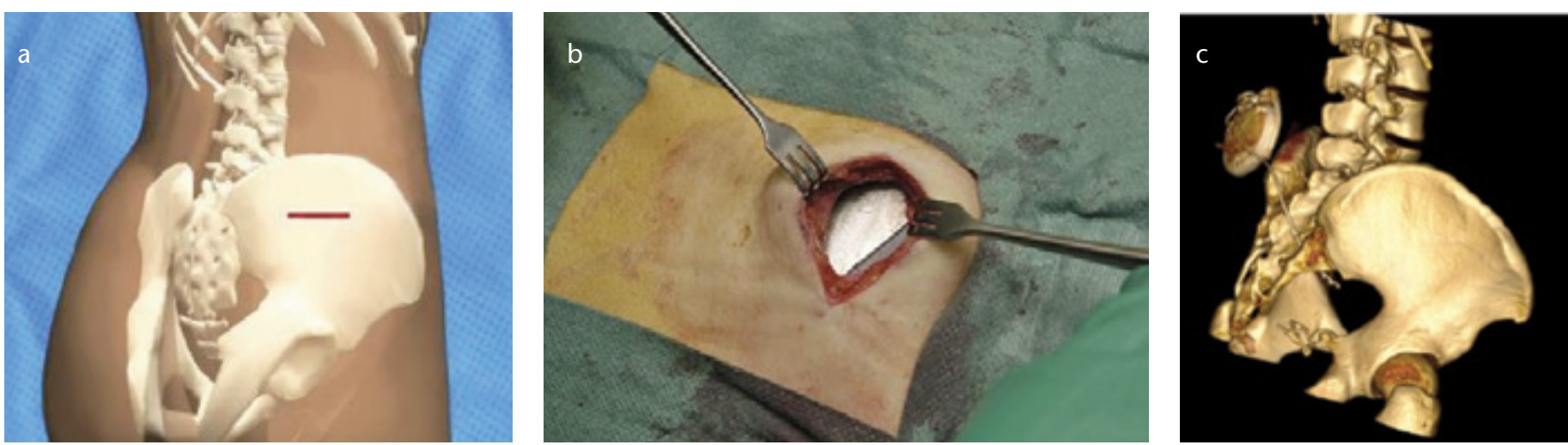

Figure 5. a-c. Schematic view of the area where the battery will be placed (a), placement of the battery (b), placement of the electrode and the battery, as seen in the three-dimensional computed tomography image (c)

and the patient is kept under observation. Previously, a spiral wire was placed in this phase. However, we now prefer placing a permanent electrode similar to that placed in the case of spinal cord stimulation owing to the migration risk during the surveillance phase as well as problems regarding the accurate observation of efficacy. Furthermore, one must be careful during the intervention that the local anesthetic agent that will be used does not permeate the neuroforamen and epidural region and affect responses.

In the subacute phase, patient is followed up for 2-4 weeks with a temporary external battery attached to the electrode. During this time, the follow-up criteria are analyzed using forms and scales prepared in accordance with indications such as fecal incontinence, constipation, pain, and urinary disorders. Furthermore, compliance of patient with the treatment, comfort in daily activities, and problems regarding the system are followed up during this period. A permanent system is planned for patients who exhibit an improvement of more than $50 \%$ in their disease condition. Quality of life questionnaires and visual analog scale are used for assessing pain during surveillance.

The final phase is the permanent system placement; upon the successful completion of the trial period of subcutaneous pocket preparation for the battery, battery placement decision is taken with the goal of establishing a permanent system. For battery placement, a depth of $2 \mathrm{~cm}$ below the elevations and the right and left abdominal lower quadrants without contraction of the iliac bone is preferred. In this technique, the electrode and the battery may be interconnected. At present, a subcutaneous pocket that is suitable for the battery is prepared in the hip immediately below the belt line, and the electrode is directly connected to the battery (Figures 5a-c). Prior to this application, patient's body and skin structure, bone protrusions, sitting-lying habits, and right- or left-handedness must be considered.

\section{Complications and Side Effects}

Sacral stimulation is accepted as an effective and safe treatment method when the patient is appropriately selected. However, as with all applications, some complications and side effects may be observed. These complications can vary depending on the chosen technique. In general, in the early period, infection, nerve damage, hemorrhage, seroma, intervention

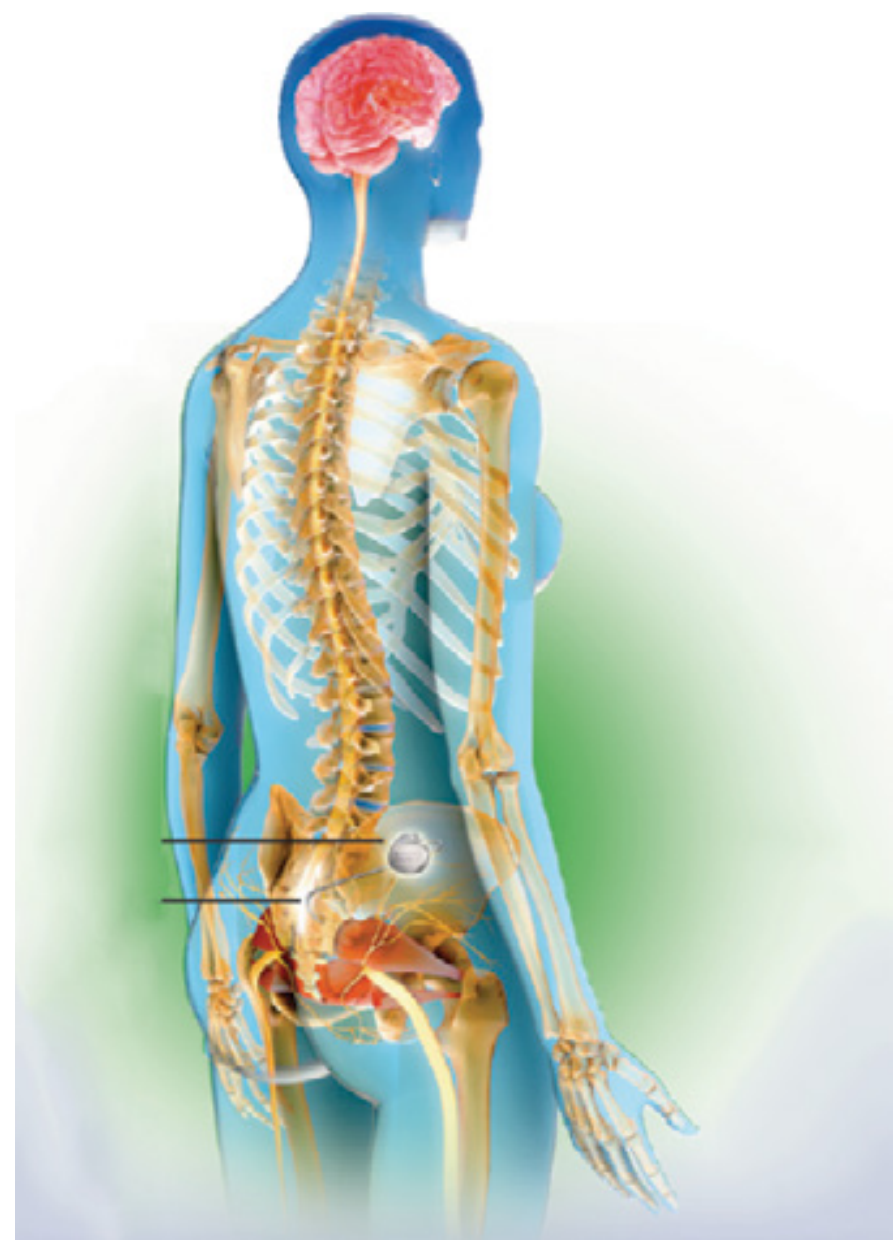

Figure 6. Peripheral and central effect of sacral stimulation: a schematic view

area pain, electrode migration, negative impact on bowel movements, long-term body reaction to the system, development of wounds in the skin owing to erosion, removal of the battery and connections, infection, problems regarding battery or electrode, programming problems, and tachyphylaxis development might be observed. 
In a multi-centered study published by Siegel et al. (63), test period and long-term complications were investigated. According to this study, the most commonly encountered problem was reported as electrode migration with $11.8 \%$. The temporary use of wire electrodes, particularly during the test periods in the past, can be cited as the main reason for the high impact of this problem. At present, the use of clamping electrodes during the test period also leads to the amelioration of this problem, and it leads to a more accurate evaluation of patient response.

Infection is also one of the commonly encountered problems that can necessitate the termination of the method, and it is reported at $6.1 \%$ in the study. Ensuring the hygiene of the intervention area, prophylactic antibiotic treatments, and training of the patient can prevent this problem.

Pain in the battery site (15.3\%) as well as in the electrode area $(5.4 \%)$ is the other common problem reported in the study. Pain in the battery site can be caused by stray voltage and unipolar stimulation sensitivity. If the problems are related to stray voltage, changes in program can be made; revision is required if the problem persists. If the pain is caused by a monopolar current, it can be switched to a bipolar current. Other causes of battery site pain can be infection, seroma, and erosion of the skin by the battery. In such cases, the problem can be resolved with appropriate treatments, but the removal of the system may also be required owing to infection. If the pain occurs because of its location, such as the belt area wherein the battery is placed or too far to the left of right, replacement can be performed with revision. Furthermore, different pains caused by nerve damage, electrode, and stimulation can occur, and in the study by Siegel, they are reported to occur at a frequency of $9 \%$. Nerve damage pain can be prevented with appropriate treatments.

Tissue resistance (impedance) measurement is helpful in the surveillance of problems regarding the system. Normal impedance is between 400 and 1500 ohms $(\Omega)$. High impedance $(>4000 \Omega$ ) indicates an open circuit, and the patient does not feel any stimulus. Open circuit is caused by broken electrode or connections. The problematic part can be revealed by reprogramming, and the problem can be solved with a new programming. However, revision is required if the problem cannot be solved with this approach. Low impedance $(<50 \Omega)$ indicates short circuit, and patient may not feel the current or he/she can feel it on different areas, for instance on the battery site. Short circuit is caused by leakage of the bodily fluids into the connections or by the contact of the wires because of damage. The problem can be solved by re-programming or revision (13).

Another problem is the re-emergence of patient's complaints. In such cases, patient's feeling of the stimulus, impedance, and battery must be checked. If the patient's feeling of stimulus gradually decreases, the problem may be regarding the battery life. Battery life is up to 7-9 years, depending on the patient's usage. If the problem involves a drained battery, a new battery is required.

\section{Conclusion}

Sacral stimulation is one of the most prominent advanced treatment methods, with several new indication areas. We know that patients are affected both peripherally and centrally during the sacral stimulation therapy. In one study, regional cerebral blood flow changes were examined with positron emission tomography during acute and chronic sacral stimulation and significant effects on awareness and alarm areas were observed in patients with urinary incontinence (Figure 6) (64). Although our knowledge is limited regarding the mechanism of action of the sacral stimulation method, it has been shown to be an effective and a safe application in many systematic studies. In the future, more evidence-based studies are required for understanding its mechanism of action and indications.

Peer-review: Externally peer-reviewed.

Acknowledgements: Author would like to thank to Medtronic company for supporting picture and photo.

Conflict of Interest: No conflict of interest was declared by the author.

Financial Disclosure: The author declared that this study has received no financial support.

\section{References}

1. Looser JD, Bonica JJ. Implanted electrical stimulators. In: John DL, editor. Bonica's Management of Pain, Lippincott Williams \& Wilkins, 3th ed. 2001;1849-50.

2. Deer T. Sacral Nerve Root Stimulation for the Treatment of Pelvic and Rectal Pain Atlas of Implantable Therapies for Pain Management. In: Timotyh RD, editor. Atlas of Implantable Therapies for Pain Management. Springer NY, 2011;95-9. [CrossRef]

3. Madersbacher $\mathrm{H}$. Conservative therapy der neurogenic disorders of micturition. Urologe A 1999;38:24-9. [CrossRef]

4. Heine JP, Schmidt RA, Tanagho EA. Intraspinal sacral root stimulation for controlled micturition. Invest Urol 1977; 15:78-82.

5. Schmidt R. Application of Neurostimulation in Urology. Neurourol Urodyn 1988;7:585-92. [CrossRef]

6. Feler CA, Whitworth LA, Fernandez J. Sacral neuromodulation for chronic pain conditions. Anesthesiology Clin North America 2003;21:785-95. [CrossRef]

7. Vaizey CJ, Kamm MA, Roy AJ, Nicholls RJ. Double-blind crossover study of sacral nerve stimulation for fecal Incontinence. Dis Colon Rectum 2000;43:298-302. [CrossRef]

8. Mowatt G, Glazener C, Jarrett M. Sacral nerve stimulation for faecal incontinence and constipation in adults. Cochrane Database Syst Rev 2007; 18:C D004464.

9. Meyerson BA, Linderoth B. Spinal cord stimulation. In: Looser JD, editor. Bonica's Management of Pain, Lippincott Williams \& Wilkins. 3th ed. 2001;1857-76.

10. Chandler MJ, Brennan TJ, Garrison DW, Kim KS, Schwartz PJ, Foreman RD. A mechanism of cardiac pain suppression by spinal cord stimulation; implications for patients with angina pectoris. Eur Hearth J 1993; 14:96-105. [CrossRef]

11. Leg WW, Chancellor MB. How sacral nerve stimulation works. Urol Clin N Am 2005;32:11-8. [CrossRef]

12. Medtronic information for prescribers. USA 2012;131-47.

13. Banakhar M, Al-Shaiji T, Hassouna M. Challenges in sacral neuromodulation; Topics in Neuromodulation Treatment, J. D. Carillo (Ed) Publisher: InTech, www.intechopen.com 2012;36-61.

14. Humphreys MR, Vandersteen DR, Slezak JM, Hollatz P, Smith CA, Smith JE, et al. Preliminary results of sacral neuromodulation in 23 children. J Urol 2006;176:2227-31. [CrossRef] 
15. Feler CA, Whitworth LA, Fernandez J. Sacral neuromodulation for chronic pain conditions. Anesthesiol Clin North America 2003;21:785-95. [CrossRef]

16. Mcjunkin TL, Wuollet AL, Lynch PJ. Sacral nerve stimulation as a treatment modality for intractable neuropathic testicular pain. Pain Physician 2009;12:991-5.

17. Kim JH, Hong JC, Kim MS, Kim SH. Sacral nerve stimulation for treatment of intractable pain associated with cauda equina syndrome. J Korean Neurosurg Soc 2010;47:473-6. [CrossRef]

18. Yang KS, Kim YH, Park HJ, Lee MH, Kim DH, Moon DE. Sacral nerve stimulation for treatment of chronic intractable anorectal pain. Korean J Pain 2010;23:60-3. [CrossRef]

19. Govaert B, Melenhorst J, van Kleef M, van Gemert WG, Baeten CG. Sacral neuromodulation for the treatment of chronic functional anorectal pain: a single center experience. Pain Pract 2010;10: 49-53. [CrossRef]

20. Martellucci J, Naldini G, Carriero A. Sacral nerve modulation in the treatment of chronic pelvic pain. Int J Colorectal Dis 2012;27: 921-6. [CrossRef]

21. Tirlapur SA, Vlismas A, Ball E, Khan KS. Nerve stimulation for chronic pelvic pain and bladder pain syndrome: a systematic review. Acta Obstet Gynecol Scand 2013;92:881-7. [CrossRef]

22. Kim YH, Moon DE. Sacral nerve stimulation for the treatment of sacroiliac joint dysfunction: A case report. Neuromodulation 2010;13:306-10. [CrossRef]

23. Lukban JC, Whitmore KE, Sant GR. Current management o interstitial cystitis. Urol Clin North Am 2002;29:649-60. [CrossRef]

24. Everaert K, Devulder J, De Muynck M, Stockman S, Depaepe H, De Looze $D$, et al. The pain cycle implications for the diagnosis and treatment of pelvic pain syndromes. Int Urogynecol J Pelvic Floor dysfunct 2001;12:9-14. [CrossRef]

25. Ghazwani YQ, Elkelini MS, Hassouna MM. Efficacy of sacral neuromodulation in treatment of bladder pain syndrome: long-term follow-up. Neurourol Urodyn 2011;30:1271-5. [CrossRef]

26. Al-zahrani AA, Elzayat EA, Gajewski JB. Long-term outcome and surgical interventions after sacral neuromodulation implant for lower urinary tract symptoms:14 years experience at 1 center. J Urol 2011;185:981-6. [CrossRef]

27. Abrams P, Blaivas J, Fowler C, Fourcroy JL, Macdiarmid SA, Siegel $\mathrm{SW}$, et al. The role of neuromodulation in the management of urinary incontinence. BJU Int 2003;91:355-9. [CrossRef]

28. Apostolidis A. Neuromodulation for intractable OAB. Neurourol Urodynami 2011;30:766-70. [CrossRef]

29. Kessler TM, La Framboise D, Trelle S, Fowler CJ, Kiss G, Pannek J,et al. Sacral neuromodulation for neurogenic lower urinary tract dysfunction: systematic review and meta-analysis. Eur Urol 2010;58: 865-74. [CrossRef]

30. Gross C, Habli M, Lindsell C, South M. Sacral neuromodulation for nonobstructive urinary retention: a meta-analysis Female Pelvic Med Reconstr Surg 2010;16:249-53. [CrossRef]

31. Schreiner L, Santos TG, Souza AB, Nygaard CC, Silva Filho IG. Electrical stimulation for urinary incontinence in women: a systematic review. Int Braz J Urol 2013;39:454-64. [CrossRef]

32. Matzel KE, Kamm MA, Stösser M, Baeten CG, Christiansen J, Madoff $R$, et al. Sacral spinal nerve stimulation for faecal incontinence: multicentre study. Lancet 2004;363:1270-6. [CrossRef]

33. Dudding TC, Pares D, Vaizey CJ, Kamm MA. Predictive factors for successful sacral nerve stimulation in the treatment of faecal incontinence: a 10-year cohort analysis. Colorectal Dis 2008;10:249-56. [CrossRef]
34. Maeda Y, Norton C, Lundby L, Buntzen S, Laurberg S. Predictors of the outcome of percutaneous nerve evaluation for faecal incontinence. Br J Surg 2010;97:1096-102. [CrossRef]

35. Brouwer R, Duthie G. Sacral nerve neuromodulation is effective treatment for fecal incontinence in the presence of a sphincter defect, pudendal neuropathy, or previous sphincter repair. Dis Colon Rectum 2010;53:273-8. [CrossRef]

36. Melenhorst J, Koch SM, Uludag O, van Gemert WG, Baeten CG. Is a morphologically intact anal sphincter necessary for success with sacral nerve modulation in patients with faecal incontinence? Colorectal Dis 2008;10:257-62. [CrossRef]

37. Dudding TC, Pares D, Vaizey CJ, Kamm MA. Sacral nerve stimulation for the treatment of faecal incontinence related to dysfunction of the internal anal sphincter. Int J Colorectal Dis 2010;25:625-30. [CrossRef]

38. Dudding TC, Vaizey CJ, Gibbs A, Kamm MA. Improving the efficacy of sacral nerve stimulation for faecal incontinence by alteration of stimulation parameters. Br J Surg 2009;96:778-84. [CrossRef]

39. Michelsen HB, Buntzen S, Krogh K, Laurberg S. Rectal volume tolerability and anal pressures in patients with fecal incontinence treated with sacral nerve stimulation. Dis Colon Rectum 2006;49: 1039-44. [CrossRef]

40. Matzel KE, Stadelmaier U, Bittorf B, Hohenfellner M, Hohenberger W. Bilateral sacral spinal nerve stimulation for fecal incontinence after low anterior rectum resection. Int J Colorectal Dis 2002;17:430-4. [CrossRef]

41. Holzer B, Rosen HR, Zaglmaier W, Klug R, Beer B, Novi G, et al. Sacral nerve stimulation in patients after rectal resection--preliminary report. J Gastrointest Surg 2008;12:921-5. [CrossRef]

42. Jarrett ME, Matzel KE, Stosser M, Baeten CG, Kamm MA. Sacral nerve stimulation for fecal incontinence following surgery for rectal prolapse repair: a multicenter study. Dis Colon Rectum 2005;48:1243-8. [CrossRef]

43. Dudding TC. Future indications for sacral nerve stimulation. Colorectal Dis 2011;13:23-8.[CrossRef]

44. Dinning PG, Fuentealba SE, Kennedy ML, Lubowski DZ, Cook IJ. Sacral nerve stimulation induces pan-colonic propagating pressure waves and increases defecation frequency in patients with slowtransit constipation. Colorectal Dis 2007;9:123-32. [CrossRef]

45. Bassotti G, Blandizzi C. Understanding and treating refractory constipation. World J Gastrointest Pharmacol Ther 2014;6:77-85.

46. Carrington EV, Evers J, Grossi U, Dinning PG, Scott SM, O'Connell $\mathrm{PR}$, et al. A systematic review of sacral nerve stimulation mechanisms in the treatment of fecal incontinence and constipation Neurogastroenterol Motil 2014;26:1222-37. [CrossRef]

47. Lundby L, Krogh K, Buntzen S, Laurberg S. Temporary sacral nerve stimulation for treatment of irritable bowel syndrome: a pilot study. Dis Colon Rectum 2008;51:1074-8. [CrossRef]

48. Jonas U, Fowler CJ, Chancellor MB, Elhilali MM, Fall M, Gajewski JB, et al. Efficacy of sacral nerve stimulation for urinary retention: results 18 months after implantation. J Urol 2001;165:15-9. [CrossRef]

49. Schmidt RA, Jonas U, Oleson KA, Janknegt RA, Hassouna MM, Siegel SW, et al. Sacral nerve stimulation for treatment of refractory urinary urge incontinence. Sacral Nerve Stimulation Study Group. J Urol 1999;162:352-7. [CrossRef]

50. Ruud Bosch JL, Groen J. Treatment of refractory urge urinary incontinence with sacral spinal nerve stimulation in multiple sclerosis patients. Lancet 1996;348:717-9. [CrossRef]

51. Vastenholt JM, Snoek G], Buschman HP, van der Aa HE, Alleman ER, ljzerman MJ. A 7 year follow- up of sacral anterior root stimulation for bladder control in patients with spinal cord injury: Quality of life and users experiences. Spinal Cord 2003;41:397-402. [CrossRef] 
52. Lombardi G, Del Popolo G. Clinical outcome of sacral neuromodulation in incomplete spinal cord injured patients suffering from neurogenic lower urinary tract symptoms. Spinal Cord 2009;47: 486-91. [CrossRef]

53. Wosnitzer MS, Walsh R, Rutman MP. The use of sacral neuromodulation for the treatment of non-obstructive urinary retention secondary to Guillain-Barre syndrome. Int Urogynecol J Pelvic Floor Dysfunct 2009;20:1145-7. [CrossRef]

54. Lombardi G, Mondaini N, Giubilei G, Macchiarella A, Lecconi F, Del Popolo G. Sacral neuromodulation for lower urinary tract dysfunction and impact on erectile function. J Sex Med 2008;5:2135-40. [CrossRef]

55. Lombardi G, Mondaini N, Macchiarella A, Cilotti A, Del Popolo G. Clinical female sexual outcome after sacral neuromodulation implant for lower urinary tract symptom (LUTS). J Sex Med 2008;5:1411-7. [CrossRef]

56. Pauls RN, Marinkovic SP, Silva WA, Rooney CM, Kleeman SD, Karram MM. Effects of sacral neuromodulation on female sexual function. Int Urogynecol J Pelvic Floor Dysfunct 2007;18:391-5. [CrossRef]

57. Aló KM, Yland M], Redko V, Feler C, Naumann C. Lumbar and sacral nerve root stimulation (NRS) in the treatment of chronic pain: a novel anatomic approach and neuro stimu- lation technique. Neuromodulation 1999;2:23-31. [CrossRef]

58. Feler CA, Whitworth LA, Brookoff D, Powell R. Recent advances: sacral nerve root stimulation using a retrograde method of lead insertion for the treatment of pelvic pain due to interstitial cystitis. Neuromodulation 1999;2:211-6. [CrossRef]

59. Aló KM, Holsheimer J. New trends in neuromodulation for the management of neuropathic pain. Neurosurgery 2002;50:690-703. [CrossRef]

60. Richter EO, Abramova MV, Aló KM. Percutaneous cepha- locaudal implantation of epidural stimulation electrodes over sacral nerve roots--a technical note on the importance of the lateral approach. Neuromodulation 2011;14:62-7. [CrossRef]

61. Falco FJ, Rubbani M, Heinbaugh J. Anterograde sacral nerve root stimulation (ASNRS) via the sacral hiatus: benefits, limitations, and percutaneous implantation technique. Neuromodulation 2003;6: 219-4.

62. Park CH, Kim BI. Sacral Nerve Stimulation Through the Sacral Hiatus, Korean J Pain 2012;25:195-7. [CrossRef]

63. Siegel SW, Catanzaro F, Dijkema H, Dijkema HE, Elhilali MM, Fowler CJ, et al. Longterm results of multicenter study on sacral nerve stimulation for treatment of urinary urge incontinence, urgencyfrequency and retention. Urology 2000;56:87-91. [CrossRef]

64. Blok BF, Groen J, Bosch JL, Veltman DJ, Lammertsma AA. Different brain effects during chronic and acute sacral neuromodulation in urge incontinent patients with implanted neurostimulators. BJU Int 2006;98:1238-43. [CrossRef] 